\title{
Support, Mentorship and Well-Being in Canadian and Croatian Faculties of Education: Professor and Student Perspectives
}

\author{
Vera Woloshyn ${ }^{1}$, Michael J. Savage ${ }^{1}$, Tanya Kaefer ${ }^{2}$, Dragana Martinovic ${ }^{3} \&$ Snezana Ratkovic $^{1}$ \\ ${ }^{1}$ Department of Educational Studies, Brock University, St. Catharines, Ontario, Canada \\ ${ }^{2}$ Graduate Studies and Research in Education, Lakehead University, Thunder Bay, Ontario, Canada \\ ${ }^{3}$ Faculty of Education, University of Windsor, Windsor, Ontario, Canada \\ Correspondence: Michael Savage, Associate Professor, Department of Educational Studies, Brock University, \\ Ontario, Canada.
}

Received: February 8, 2021

Accepted: March 15, 2021

Online Published: March 29, 2021

doi:10.20849/jed.v5i1.880

URL: https://doi.org/10.20849/jed.v5i1.880

\begin{abstract}
The purpose of this quantitative study was to examine professors' and Master of Education (MEd) students' well-being, support, academic self-efficacy and mentorship in Canada and Croatia. Overall, 118 professors and 98 MEd students from three universities in Canada and three universities in Croatia completed the online surveys in English and Croatian, respectively. The frameworks of self-determination theory and relational cultural theory informed interpretation of our findings. Results suggest that for professors in both countries, personal support, professional support and academic self-efficacy predict professional well-being. Only personal support predicts personal well-being in Canadian professors, while personal support and academic self-efficacy predicts personal well-being in Croatia. Personal and professional support was also associated with positive mentorship practices in Canada. Students in both countries, who felt supported professionally and personally, reported greater professional and personal well-being respectively. Self-efficacy may make a difference for Croatian students but seemed to have little unique impact on Canadian students. Studying part-time in Canada was associated with higher personal and professional well-being but was associated with lower personal well-being in Croatia. Mentorship practices seemed to have little effect on well-being in either country. Overall, professors reported higher well-being and support than M.Ed. students. We conclude with recommendations that would be informative for university administrators, graduate programs, and services interested in the well-being of professors and graduate students.
\end{abstract}

Keywords: well-being, graduate education, psycho-socio-emotional support, mentorship, self-determination theory, relational cultural theory

\section{Introduction}

Higher education holds a critical role in the global economy (Larson et al., 2019; Seipel \& Larson; 2018). Graduate studies are recognized as essential for knowledge production, knowledge mobilization, and ongoing professional training (Rose, 2013). Effective graduate education enhances the development of students' critical, empirical, and creative thinking skills; academic skills (e.g., research and teaching skills); transferable skills (e.g., personal, interpersonal, and career-related skills); and induction into the professions (Rose, 2013). Master's level studies have particularly been recognized as critical prerequisites for pursuing advanced academic and professional careers.

It has been argued that a master's degree is the new bachelor's degree, a degree "essential for job seekers to stand out" in a competitive workforce (Pappano, 2011, para. 13). Enrollment demographics, field offerings, and delivery formats of master's degree programs have changed radically in the last decade, creating new challenges and new opportunities for policymakers, curriculum developers, staff, faculty, and students in graduate education (Blagg, 2018). In Canada, the number of master's level enrolments has increased steadily over the past three decades (Wall, Zhao, Ferguson, \& Rodriguez, 2018). At the same time, graduate programming and student demographic patterns have also changed dramatically. Many higher education institutions offer course-based, part-time, flex-time, distance and blended programs, with increasing numbers of working, mature, and minority students enrolled in graduate studies (Higher Education Quality Council of Ontario, 2018). 
Education represents the second-most common area of focus across all master's level programs and is the most common field of study among women in Canada (Wall et al., 2018). Individuals who graduate with a master's degree in Education (MEd) typically gain and/or maintain employment in the field, working either directly in classrooms or holding administrative and/or supervisory positions (Wall et al., 2018). In Croatia, a master's degree is required for teachers in primary and secondary schools regardless if they are generalists or subject specialists (European Agency for Special Needs and Inclusive Education, 2018). As in Canada, where 84\% of elementary school teachers and 59\% of secondary school teachers are women (Statistics Canada, 2016), in Croatia the majority of teachers are also women, with women representing $78 \%$ of elementary school teachers and $67 \%$ of secondary school teachers (Organization for Economic Co-operation and Development, 2019). Women also represent the majority of student enrolments in MEd programs in Croatian Faculties of Education, with female student enrolments increasing by four percent between 2015 and 2019. Enrolment increases in MEd programs are expected to continue over the near future as Croatia anticipates a teacher shortage (European Commission, 2019).

Graduate students in MEd programs are exposed to high levels of stress due to the intensity of graduate studies, as well as the teaching profession. Teaching and school administration have been recognized as stressful and emotionally intense occupations globally (Buric, Sliskovic, \& Penezi, 2019). Teachers routinely experience stressors related to managing unmotivated students, maintaining classroom management, and being critiqued and scrutinized by the public. In addition, teachers frequently experience policy and curricular changes, role conflict and ambiguity, and administrative demands (Buric et al., 2019). Teachers who experience high levels of stress in the workplace may also negatively impact the well-being of their students (Sisask et al., 2013).

While there is ample research conducted with school teachers and students (e.g., Frank, Reibel, Broderick, Cantrell, \& Metz, 2015), there is less research pertaining to the experiences of MEd students and professors. Exploring the subjective reports of well-being among MEd students and professors within Faculties of Education holds dual urgency for promoting well-being within higher education and communities at large. In this paper, we investigated well-being, relational support, and mentorship among and between professors and MEd students in Faculties of Education in Canada and Croatia. We discuss findings in context of organizational dynamics and propose recommendations for promoting well-being in higher education.

\subsection{Well-Being}

Well-being is considered to be a dynamic state that reflects, in part, the interplay between individuals' current psychological, social, cultural and physical status, capacities, skills and resources and the specific challenges that they face at any one time (Dodge, Daly, Huyton, \& Sanders, 2012; Manwell et al., 2015). While several frameworks have been proposed for well-being, or what is sometimes referred to as wellness, Anderson (2019) posits the existence of four common critical concepts that are embedded across all frameworks. The first is that well-being is multidimensional, encompassing physical, psychological and emotional wellness. Second, these dimensions are interdependent so that well-being is reflective of the intersections between them. Third, well-being is positive-oriented so that the sense of wellness is more than the absence of negative factors such as poor physical health, mental illness, limited ability, or poor self-esteem. Last, well-being is growth-oriented, representing continuous improvement and advancement. In these ways, well-being is an "interconnected, fluid and evolving approach for living life" (Anderson, 2019, p. 3).

Both Canada and Croatia have received waves of refugees over the previous two decades. Croatia, however, has received far more refugees than Canada has. For example, in 2015-2016 Canada accepted 25,000 refugees from the Middle East (Houle, 2019) while during the same time frame over 800,000 refugees from the Middle East sought shelter in Croatia (Marsanic, Franic, \& Aurkovic, 2017). Displaced persons within their border has been a decades-long issue for the Croatian government as in 1993, the displaced or refugee population represented more than $20 \%$ of the total population of Croatia, which was 4.8 million people at that time (Marsanic et al., 2017). The displaced population in Croatia has faced severe traumatic events and the healthcare, employment and mental health needs of this population have taxed the resources of the Croatian government (Marsanic et al., 2017).

As it is well recognized that negative social-cultural-political conditions including income inequality, unemployment, underemployment, social welfare, war, civil and political instability, marginalization, racism, and/or discrimination and displaced persons may work to exacerbate individuals' experiences of poor mental health and well-being (Jovanović, 2019; Manwell et al., 2015). In these contexts, individuals' abilities to manage stress, maintain work-life balance, develop resilience, and practice effective coping skills are recognized as critical factors for well-being and role satisfaction (Darabi, Macaskill, \& Reidy, 2016; Dodge et al., 2012). We chose to compare the Canadian and Croatian contexts to examine the effects of social-political conditions on the well-being and support of graduate students and professors. 


\subsection{Professor and Graduate Student Well-Being}

There is growing recognition that institutions of higher learning are stressful places and that academia is a stressful occupation. Universally, professors' report experiencing stressors related to simultaneously mounting expectations for research and scholarly productivity in context of increased instructional workloads, administrative duties and student expectations (Kinman \& Wray, 2013; Kinman, 2019). Graduate students, similarly, report stressors related to demanding and uncertain workloads, work-life imbalances, sense of isolation, financial concerns including restricted access to employment, funding, and scholarship opportunities while on campus, and limited employment opportunities post-graduation (Kim, 2016). Experiences of intense worry, low mood, disturbed sleep, and diminished self-care practices are common (Evans, Bira, Beltran Gastelum, Todd Weiss, \& Vanderford, 2018). Collectively, these stressors contribute to increased experiences of stress, emotional exhaustion, depersonalization, and overall sense of poor well-being among professors and graduate students (Jovanovic, 2019; Gulati, Lele Mookerjee, \& Rajput, 2018). A 2005 study showed that $42 \%$ of university students reported feeling elevated distress, compared with $17 \%$ of similarly aged non-students (Adlaf, Demers, \& Gliksman, 2005). However, this data was not broken down by undergraduate or graduate program.

Graduate students typically benefit from their supervisors' research and financial support, career guidance, and psycho-socio-emotional support (Woloshyn, Savage, Ratkovic, Hands \& Martinovic, 2019). Supervisory and mentoring relationships are critical to the graduate student experience, success and well-being (Rose, 2013). Faculty, in turn, appear to be increasingly aware of the importance of creating inclusive and positive learning environments that promote and sustain graduate student well-being (Woloshyn et al., 2019). While the provision of academic accommodations and on-campus services are recognized as important to these efforts, they are often perceived as secondary to the need to develop authentic and caring relationships, and mentorship in graduate education.

Graduate students who experience a lack of well-being are more likely to report academic difficulties, terminate their studies, or extend their completion rates relative to their peers who report well-being (Neves \& Hillman, 2018). This may be particularly important in Croatia where postsecondary graduation rates are low (European Commission, 2019). While professors may not necessarily leave their academic positions because of career-related stressors, experiencing poor well-being may negatively impact their productivity, motivation for work, sense of optimism, and overall levels of engagement (Gulati et al., 2018).

It is realistic to assume that a proportion of graduate students and professors will, at some point, experience a compromised sense of well-being (Evans et al., 2018; Henning et al., 2018). Many higher education institutions across the globe have initiated programs and services to support students' well-being while on campus. These services, however, tend to be tailored for, and almost exclusively used by, undergraduate students, leaving the needs of graduate students and professors potentially unmet (Jaworska, De Somma, Fonseka, Heck, \& MacQueen, 2016; Thorley, 2017). The primary purpose of this research study was to explore the relationships and intersections between perceptions of well-being, relational support, and mentorship among professors and MEd students in Canadian (Ontario) and Croatian Faculties of Education.

\subsection{Theoretical Frameworks}

Self-determination theory (Deci \& Ryan, 1985; Ryan \& Deci, 2000) and relational cultural theory (Miller, 1976; Miller \& Stiver, 1997) were used to guide this research study. Both theories help to contextualize mechanisms responsible for graduate student and professor well-being in higher education including the relational activity of mentoring.

\subsubsection{Self-Determination Theory (SDT)}

According to SDT, individuals are inherently motivated towards self-actualization, with their sense of integrity, growth, and well-being determined through the attainment of three basic and innate psychological needs including autonomy, competence, and connectedness to others (Deci \& Ryan, 1985; Ryan \& Deci, 2000) Attainment of these three needs has been positively associated with subjective measures of well-being as well as inversely related to mental health disorders such as depression and anxiety (Ng et al., 2012). Functioning and well-being are enhanced to the extent that individuals demonstrate control, choice and autonomy over their career and life choices; experience a sense of achievement, success, challenge and self-efficacy; and engage in caring, supportive and empathetic interpersonal relationships (Ryan \& Deci, 2000). In higher education, engagement in meaningful work and interactions with supportive and caring personal relationships promotes and/or moderates academic success, career satisfaction, and sense of well-being (Larson et al., 2019; Seipel \& Lawson, 2018). 
It is well-established that the contexts and/or environments in which individuals live and work affect their realization of the three basic psychological needs (Deci \& Ryan, 1985). In higher education, context or environment is typically reflected through relational experiences within the academic department. These experiences may include support from critical others, such as department chairs, deans, and senior administrators. Environment may also include providing constructive feedback, recognizing contributions and achievements, granting tenure and promotion, and/or renewing contract positions (Larson et al., 2019; Seipel \& Larson, 2018).

\subsubsection{Relational Cultural Theory (RCT)}

Within the RCT framework, growth-fostering relationships include a mutual sense of worth, clarity, action, knowledge and productivity, zest, and desire for ongoing connection lead to increases in well-being (Miller, 1986; Miller \& Stiver, 1997). Mentoring has the potential to be one such growth-fostering relational process, providing individuals with opportunities to come to know themselves better, as well as experience a positive sense of self-worth, self-esteem, and/or competency through engagement in genuine discussions in which they feel heard and, in turn, hear others (Jordan, 2010). These critical conversations may also provide motivation to seek out additional connections. In these ways, growth-fostering relationships are characterized by mutual empathy, relational authenticity, and mutual empowerment that serve to deepen learning experiences for students and regenerate professors (Shwartz \& Holloway, 2012).

Meaningful, high-quality relationships are associated with well-being and functioning and may even exist in the presence of power and/or role differentials such as in the case of professors and graduate students (Jordan, 2010). In one survey, 511 full-time professors working in public and private institutions ranked the quality of their interpersonal relationships as the primary determinant of their overall sense of well-being (English \& Avakian, 2012). In the same way, graduate students reported a positive association between caring formal as well as informal mentoring relationships and learning and academic success. Students also reported enhanced sense of safety, agency, empowerment, as well as enhanced self-esteem, self-worth and connectivity as a function of these relationships (Lucey \& White, 2017; Schwartz \& Holloway, 2012, 2014).

\subsection{Purpose}

There is relatively little research available exploring the relational and well-being experiences of MEd students and their professors. Given the increasing numbers of student enrollments in MEd programs and the extended impacts on the learning, well-being and success experiences of youth in their care, it seems imperative to study MEd students' and their professors' experiences of well-being within academia. In this study, we explored the relationships between subjective reports of well-being, personal and professional support, and mentoring among professors and MEd students in Canada and Croatia. The following research questions guided this correlational comparative study:

1. What is the relationship between perceptions of well-being, support, academic self-efficacy and mentorship practices among professors and MEd students? Do these relationships differ across Canada and Croatia?

2. What variables are predictive of subjective well-being? Do these predictors differ across professors and MEd students in Canada and Croatia?

3. What variables are predictive of engagement with positive mentorship practices? Do these predictors differ across professors and MEd students Canada and Croatia?

4. Do professors and MEd students differ in their sense of well-being, support, academic self-efficacy and mentorship? Do these patterns differ across Canada and Croatia?

\section{Method}

The findings reported here represent the first wave of data emerging from a comparative explanatory mixed-methods investigation of perceptions of well-being and graduate mentorship in Faculties of Education in Canada (Ontario) and Croatia.

\subsection{Recruitment}

MEd students from six participating universities (three in Canada, and three in Croatia) were invited to participate in this study. A multi-layered, email recruitment procedure was used in which letters of invitation and informed consent forms, including a hyperlink to the online survey, were sent out through the MEd student email listservs at participating universities. Similar invitations were extended to professors in both countries using their publicly available email addresses. In Canada, recruitment materials were sent out in English, while in Croatia the materials were sent out in English and Croatian. 


\subsection{Online Survey}

The online survey for the MEd students consisted of 78 questions, including 11 demographic questions, 3 standardized instruments and 2 open-ended questions. The online survey for professors consisted of 77 questions, including 10 demographic questions, 3 standardized instruments and 2 open-ended questions. The surveys were translated from English to Croatian by the authors, with demographic questions adjusted to reflect national contexts.

\subsubsection{Demographic Questions}

Professors were asked to identify their gender, age, whether their position was permanent, academic rank, the number of students they have mentored and whether they supervised MEd theses. We did not ask Croatian professors to distinguish between their roles as thesis supervisors and committee members as all professors are required to serve as research advisors. The MEd students were asked to identify their age, gender, study status (i.e., part-time, full-time) and university affiliation.

\subsubsection{Skovholt Practitioner Professional Resiliency and Self-Care Inventory (Skovolt, 2016)}

This inventory is a 38-item instrument designed to encourage reflection-on-practice. It provides a measure of stress and resilience for practitioners and students involved in the caring professions, including the field of education. The inventory is based on a 4-factor structure including professional vitality, personal vitality, professional stress and personal stress. For the purposes of this study, four new subscales were extracted from the original instrument in order to examine perceptions of well-being and support.

Items that addressed support were isolated, with four items identified as professional support (e.g. "My work environment is like a greenhouse -where everything grows-because the conditions are such that I feel supported in my professional work") and used to develop the professional support subscale (Cronbach's alpha of .68). In the current data this subscale was not normally distributed, with a Shapiro-Wilk score of $.98(p=.011)$. Examination of histogram plots indicated that this variable had a small negative skew. Five items were identified as personal support, (e.g. "I have a supportive community where I feel connected") with a Cronbach's alpha of .74. In the current data this subscale was also not normally distributed, with a Shapiro-Wilk score of .96 $(p<.001)$. Examination of the histogram plots indicated that this variable had a negative skew. Both of these scales were used primarily as predictor variables, making them robust to violations of normal distribution of scores (Keith, 2019). When the variables were used as dependent variables in regression models, assumptions of those models, including normal distribution of residuals, were met.

The remaining inventory items were used as measures of well-being. The 13 items in the professional vitality (e.g. "I find my work as a professor/student to be meaningful") and professional stress (e.g. "I have found a way to have high standards for my work yet avoid unreachable perfectionism") sections were collapsed to create the professional well-being subscale which had a Cronbach's alpha of .75. In the current data this subscale was normally distributed, with a Shapiro-Wilk score of $.98(p=.134)$. Similarly, the remaining 16 items in the personal vitality (e.g. "I have plenty of humor and laughter in my life") and personal stress (e.g. "I am able to cope with significant losses in my life") sections were collapsed into the personal well-being subscale, with a Cronbach's alpha of .80. In the current data, this subscale was normally distributed, with a Shapiro-Wilk score of $.98(p=.085)$ Examination of histogram plots confirmed approximately normal distributions with slight non-significant negative skews. These measures of well-being were used as dependent variables in the data analyses. Greater consideration was given to the residual distribution than the individual variable distributions as hierarchical linear regression comprised the primary analyses. Residual distribution information is presented alongside those analyses in the results section.

\subsubsection{Academic Self-Efficacy}

This measure consisted of one item ("I am capable of succeeding in my academic career") scored on a 5-point Likert scale. Created by the researchers, it measures how efficacious MEd students and professors feel about their academic and career achievement.

\subsubsection{Mentorship Experience Scale (Gullan et al., 2016)}

This instrument consists of 24 items designed to assess university students' perceptions of the quality of their mentoring relationships with professors, coaches and/or administrative staff across four domains; challenge, authenticity, commitment, and community. Participants were instructed to reflect on either formal or informal experiences when completing the measure. The instrument was modified for use with professors by having them reflect on the experience of being a mentor, as opposed to being a mentee. For example, the item, "My relationship with my mentor is personal" became "My relationship with my mentee is personal." Cronbach's alpha was .94 for 
the student instrument and .84 for the professor instrument. For the purposes of this study, total scores were used as a measure of positive mentorship practices.

\subsection{Data Analyses}

Descriptive statistics and Pearson correlations were completed to examine the relationships between professor and MEd perceptions of well-being, support, academic self-efficacy, and mentorship practices. T-tests and MANOVAs were used to determine if differences exist between countries and participant groups. Hierarchical regression analyses were completed to examine factors that predicted professional and personal well-being.

Separate analyses for the Canadian and Croatian participants were carried out in order to compare patterns across countries and participant groups. Normal distribution of residuals based on P-plots was found for all reported analyses. Non-significant Glejser tests for heteroskedasticity and Variance Inflation Factor (VIF) values of fewer than 5.0, suggested that the assumptions of multi-collinearity and normality were met. Relationships between professors' involvement in graduate programs and their perceptions of well-being, support and mentorship were also explored. Multiple linear regressions were completed for each of mentorship, personal well-being, professional well-being, personal support, and professional support.

MANOVAs were completed in order to examine potential differences between professors' and students' perceptions of well-being, support, and mentorship. As no differences emerged across formal and informal mentoring experiences, mentoring was analyzed as a collective activity. Participants' personal well-being, professional well-being, personal support, professional support, mentorship practices, and academic self-efficacy scores were used as dependent variables and participant status (student, professor) was used as an independent variable.

\section{Results}

Correlation and regression results for professors and MEd students are reported first, with comparisons between these two groups presented last.

\subsection{Participants}

Participants included 118 professors and 98 MEd students in targeted Faculties of Education in Canada (Ontario) and Croatia. Table 1 outlines demographic information for these participants including gender, age, and status. Canadian participants were significantly older than their Croatian counterparts [professors: $\chi 2(4)=19.55, \mathrm{~N}=116$, $\mathrm{p}=.001$; MEd students: $\chi 2(5)=24.92, \mathrm{~N}=96, \mathrm{p}<.001$ ]. Significantly more Canadian professors with higher ranks completed the study than did Croatian professors, $\chi 2(4)=22.22, \mathrm{~N}=102, \mathrm{p}=.001$. Significantly more Canadian male MEd students participated in this study than did Croatian male MEd students: $\chi 2(2)=11.72, \mathrm{~N}=98$, $\mathrm{p}=.003$. There were no other significant differences across the participant groups (see Table 1 ).

Table 1. Demographics of participants

\begin{tabular}{lllll}
\hline & Canada & & Croatia \\
\hline & Professors & MED Students & Professors & MEd Students \\
\hline $\mathrm{N}$ & 75 & 38 & 28 & 60 \\
\hline $\begin{array}{c}\text { Gender } \\
\text { Male }\end{array}$ & $26 \%$ & $37 \%$ & $32 \%$ & $3 \%$ \\
$\quad$ Female & $74 \%$ & $63 \%$ & $68 \%$ & $97 \%$ \\
\hline Age & & & & \\
Under 20 & 0 & 0 & 0 & $1.7 \%$ \\
$21-25$ & 0 & $42.1 \%$ & 0 & $82.8 \%$ \\
$26-30$ & 1.1 & $10.5 \%$ & 0 & $6.9 \%$ \\
$31-40$ & $6.7 \%$ & $23.7 \%$ & $39.3 \%$ & $8.6 \%$ \\
Over 40 & $92 \%$ & $23.7 \%$ & $60.7 \%$ & 0 \\
\hline Permanency & $79.8 \%$ & - & $82.1 \%$ & - \\
\hline Part-time studies & - & $13.2 \%$ & - & $16.7 \%$ \\
\hline
\end{tabular}




\subsection{Professors}

Simple correlations were completed to examine relationships between professors' perceptions of support, well-being, academic self-efficacy, and mentorship. All variables were correlated, with the exception of professors' perceived academic self-efficacy, which was not related to their perceptions of professional support or mentorship practices (Table 2).

Table 2. Correlation matrix for professor well-being, support, academic self-efficacy and mentorship

\begin{tabular}{lllllll}
\hline & 1 & 2 & 3 & 4 & 5 & 6 \\
\hline 1. Professional well-being & - & & & & & \\
\hline 2. Personal well-being & $.66^{* *}$ & - & & & & \\
\hline 3. Professional support & $.51^{* *}$ & $.30^{*}$ & - & & & \\
\hline 4. Personal support & $.58^{* *}$ & $.67^{* *}$ & $.43^{* *}$ & - & & \\
\hline 5. Academic self-efficacy & $.39^{* *}$ & $.45^{* *}$ & .12 & $.31^{*}$ & - & \\
\hline 6. Mentorship & $.37^{* *}$ & $.32^{*}$ & $.35^{* *}$ & $.37^{* *}$ & .12 & - \\
\hline
\end{tabular}

${ }^{*} p<.01 ;{ }^{* *} p<.001$

Differences between the two countries were examined (see Table 3). Overall, Canadian professors reported higher personal well-being, $t(102)=2.05, p=.043$ and academic self-efficacy, $t(102)=2.62, p=.010$, than Croatian professors, who reported higher professional support relative to their Canadian peers, $t(94.48)=-2.24, p=.028$. These t-test reported a minimum observed power of .65 .

Table 3. Means and standard deviations of professor and MEd student perceptions of well-being, support, mentorship, and academic self-efficacy

\begin{tabular}{lllll}
\hline & Canadian & & Croatian \\
\hline & Professor & MEd Student & Professor & MEd Student \\
\hline Professional well-being $^{\mathrm{a}}$ & $53.06(6.52)$ & $50.45(5.80)$ & $54.07(4.78)$ & $51.14(3.82)$ \\
\hline Personal well-being $^{\mathrm{b}}$ & $64.12(8.60)$ & $57.29(8.41)$ & $60.55(6.96)$ & $61.02(6.99)$ \\
\hline Professional support $^{\mathrm{c}}$ & $14.36(3.36)$ & $14.73(2.83)$ & $15.32(1.74)$ & $13.54(2.35)$ \\
\hline Personal support $^{\mathrm{d}}$ & $21.77(2.69)$ & $20.11(3.08)$ & $21.41(2.28)$ & $21.11(3.88)$ \\
\hline Mentorship $^{\mathrm{e}}$ & $91.33(8.92)$ & $95.18(14.09)$ & $91.78(.10 .28)$ & $92.08(16.48)$ \\
\hline Academic self-efficacy $^{\mathrm{f}}$ & $4.54(.74)$ & $4.48(.57)$ & $4.11(.83)$ & $4.35(.63)$
\end{tabular}

${ }^{\mathrm{a}}$ Professional well-being score $=65 ;{ }^{\mathrm{b}}$ Personal well-being score $=80 ;{ }^{\mathrm{c}}$ Professional support score $=20 ;{ }^{\mathrm{d}}$ Personal support score $=25 ;{ }^{\mathrm{e}}$ Mentorship score $=120 ;{ }^{\mathrm{f}}$ Academic self-efficacy score $=5$

A hierarchical regression analysis was completed to identify factors that predicted professional well-being. In step one of the regression, gender and permanency were entered. In step two, academic self-efficacy, perceived personal support and perceived professional support were entered. Gender was predictive at the first step with Canadian men reporting higher professional well-being than Canadian women (Table 4). Each step two variable also accounted for a significant amount of variability with respect to Canadian professors' perceptions of professional well-being. Similar patterns emerged for Croatian professors, although there was no significant effect for gender at step one. Overall, personal and professional support and perceptions of academic self-efficacy predicted professors' perceptions of professional well-being across both countries, with gender only predicting professional well-being for Canadian participants. 
Table 4. Hierarchical regression analysis of variables predicting professor professional and personal well-being in Canada and Croatia

\begin{tabular}{|c|c|c|c|c|c|c|c|}
\hline & $\Delta \mathrm{R}^{2}$ & $B^{\mathrm{a}}$ & $\mathrm{SE}$ & $t$-value & $p$-value & $s r^{2 \mathrm{~b}}$ & Observed power \\
\hline \multicolumn{8}{|l|}{ Professional well-being } \\
\hline \multicolumn{8}{|l|}{ Canada } \\
\hline Step 1 & .09 & & & & .033 & & .66 \\
\hline Gender & & -3.35 & 1.36 & -2.46 & .016 & .08 & \\
\hline Permanency & & .822 & 1.86 & .44 & .660 & .003 & \\
\hline Step 2 & .43 & & & & $<.001$ & & .99 \\
\hline Academic self-efficacy & & 2.35 & .87 & 2.71 & .008 & .05 & \\
\hline Professional support & & .44 & .19 & 2.36 & .021 & .04 & \\
\hline Personal support & & .98 & .24 & 4.13 & $<.001$ & .12 & \\
\hline \multicolumn{8}{|l|}{ Croatia } \\
\hline Step 1 & .10 & & & & .275 & & .29 \\
\hline Gender & & -2.31 & 1.94 & -1.19 & .244 & .05 & \\
\hline Permanency & & -2.49 & 2.09 & -1.19 & .245 & .05 & \\
\hline Step 2 & .55 & & & & $<.001$ & & .99 \\
\hline Academic self-efficacy & & -.26 & 1.04 & -.253 & .802 & .001 & \\
\hline Professional support & & 1.09 & .38 & 2.90 & .008 & .13 & \\
\hline Personal support & & 1.18 & .36 & 3.26 & .004 & .17 & \\
\hline \multicolumn{8}{|l|}{ Personal well-being } \\
\hline \multicolumn{8}{|l|}{ Canada } \\
\hline Step 1 & .05 & & & & .195 & & .40 \\
\hline Gender & & -2.47 & 1.87 & -1.32 & .190 & .02 & \\
\hline Permanency & & 2.32 & 2.54 & .91 & .365 & .01 & \\
\hline Step 2 & .45 & & & & $<.001$ & & .99 \\
\hline Academic self-efficacy & & 2.03 & 1.18 & 1.72 & .091 & .02 & \\
\hline Professional support & & -.04 & .26 & -.169 & .866 & $<.001$ & \\
\hline Personal support & & 2.01 & .322 & 6.23 & $<.001$ & .29 & \\
\hline \multicolumn{8}{|l|}{ Croatia } \\
\hline Step 1 & .03 & & & & .664 & & .11 \\
\hline Gender & & -1.56 & 2.92 & -.53 & .599 & .01 & \\
\hline Permanency & & -2.41 & 3.15 & -.77 & .452 & .02 & \\
\hline Step 2 & .63 & & & & $<.001$ & & .99 \\
\hline Academic self-efficacy & & 3.2 & 1.48 & 2.16 & .042 & .07 & \\
\hline Professional support & & .84 & .53 & 1.57 & .131 & .04 & \\
\hline Personal support & & 1.52 & .52 & 2.95 & .007 & .13 & \\
\hline
\end{tabular}

${ }^{a}$ Unstandardized regression coefficient

${ }^{\mathrm{b}}$ Squared semi-partial correlation

Similar to the identifying factors that predicted professional well-being, a hierarchical regression analysis identified factors that predicted personal well-being. In step one, gender and permanency were entered. In step two, 
academic self-efficacy, perceived personal support and perceived professional support were entered. Personal support significantly predicted personal well-being for professors in both countries (Table 4). In the Croatian sample, there was a significant effect of academic self-efficacy on personal well-being.

The influences of support and well-being factors for engagement in positive mentorship practices were also explored. In step one of the regression, gender and permanency were entered. In step two, academic self-efficacy, perceived personal support and perceived professional support were entered. A third step was also included in which perceived personal support and perceived professional well-being were entered. While overall change in $R^{2}$ between steps one and two was significant for Canadian participants, perceived professional and personal support only marginally predicted engagement in positive mentorship practices (Table 5). In the Croatian sample, a similar pattern emerged with a significant change in $R^{2}$ at step two. Neither perceived support nor well-being, predicted mentorship practices. Overall, personal and professional support collectively predicted mentorship practices, but their predictive ability for this variable was intertwined so that they explained more variance when combined than when each variable was uniquely examined.

Table 5. Hierarchical regression analysis of variables predicting professor engagement with positive mentorship practices in Canada and Croatia

\begin{tabular}{|c|c|c|c|c|c|c|}
\hline & $\Delta \mathrm{R}^{2}$ & $B^{\mathrm{a}}$ & $\mathrm{SE}$ & $t$-value & $p$-value & $s r^{2 \mathrm{~b}}$ \\
\hline \multicolumn{7}{|l|}{ Canada } \\
\hline Step 1 & .001 & & & & .98 & \\
\hline Gender & & .002 & .09 & .19 & .99 & $<.001$ \\
\hline Permanency & & .02 & .12 & .19 & .85 & .001 \\
\hline Step 2 & .18 & & & & .005 & \\
\hline Academic self-efficacy & & -.06 & .07 & -.89 & .377 & .01 \\
\hline Professional support & & .03 & .02 & 1.96 & .055 & .05 \\
\hline Personal support & & .04 & .02 & 1.99 & .050 & .05 \\
\hline Step 3 & .01 & & & & .75 & \\
\hline Professional well-being & & .01 & .01 & .60 & .550 & .005 \\
\hline Personal well-being & & .001 & .01 & .112 & .910 & $<.001$ \\
\hline \multicolumn{7}{|l|}{ Croatia } \\
\hline Step 1 & .05 & & & & .566 & \\
\hline Gender & & -.18 & .19 & -.969 & .342 & .04 \\
\hline Permanency & & .07 & .21 & .32 & .748 & .004 \\
\hline
\end{tabular}

Step 2

\begin{tabular}{lccccc}
\hline Academic self-efficacy & .09 & .12 & .72 & .478 & .02 \\
\hline Professional support & .05 & .05 & 1.06 & .300 & .03 \\
\hline Personal support & .08 & .04 & 1.74 & .096 & .09 \\
\hline Step 3 & .12 & & & & .115 \\
\hline Professional well-being & .05 & .02 & 1.96 & .065 & .10 \\
\hline Personal well-being & .01 & .02 & .73 & .473 & .01 \\
\hline
\end{tabular}

${ }^{a}$ Unstandardized regression coefficient

${ }^{\mathrm{b}}$ Squared semi-partial correlation 
Finally, relationships between professors' involvement in graduate programs and their perceptions of well-being, support and mentorship were explored. Multiple linear regressions were completed for each of mentorship, personal well-being, professional well-being, personal support, and professional support. The approximate number of students mentored and supervisor status (Canadian data only) were simultaneously entered for this analysis. For Canadian professors there was a significant effect of acting as a thesis supervisor on personal and professional well-being (Table 6). For the Croatian sample, the number of students mentored positively predicted engagement in positive mentorship practices, professional well-being, and perceived personal well-being, but not personal support or professional support.

Table 6. Impacts of participation in graduate program on professor well-being, support and mentorship

\begin{tabular}{|c|c|c|c|c|c|}
\hline Outcome variable & $B^{\mathrm{a}}$ & $\mathrm{SE}$ & $t$-value & $p$-value & $s r^{2 \mathrm{~b}}$ \\
\hline \multicolumn{6}{|l|}{ Canada } \\
\hline \multicolumn{6}{|l|}{ Professional well-being } \\
\hline Number of students mentored & -1.29 & .743 & -1.74 & .087 & .04 \\
\hline Thesis supervisor* & 4.82 & 2.13 & 2.26 & .027 & .07 \\
\hline \multicolumn{6}{|l|}{ Personal well-being } \\
\hline Number of students mentored & -.69 & .97 & .72 & .477 & .01 \\
\hline Thesis supervisor* & 6.86 & 2.77 & 2.48 & .016 & .08 \\
\hline \multicolumn{6}{|l|}{ Professional support } \\
\hline Number of students mentored & -.48 & .40 & -1.22 & .227 & .02 \\
\hline Thesis supervisor & .60 & 1.13 & .53 & .597 & .004 \\
\hline \multicolumn{6}{|l|}{ Personal support } \\
\hline Number of students mentored & -.38 & .28 & -1.35 & .18 & .02 \\
\hline Thesis supervisor $^{\dagger}$ & 1.60 & .81 & 1.97 & .053 & .05 \\
\hline \multicolumn{6}{|l|}{ Mentorship } \\
\hline Number of students mentored & .03 & .05 & .61 & .549 & .005 \\
\hline Thesis supervisor & .04 & .13 & .33 & .745 & .002 \\
\hline \multicolumn{6}{|l|}{ Croatia } \\
\hline \multicolumn{6}{|l|}{ Professional well-being } \\
\hline Number of students mentored* & 2.71 & .545 & 4.97 & $<.001$ & .49 \\
\hline \multicolumn{6}{|l|}{ Personal well-being } \\
\hline Number of students mentored* & 2.16 & 1.04 & 2.07 & .048 & .14 \\
\hline \multicolumn{6}{|l|}{ Professional support } \\
\hline Number of students mentored & .13 & .28 & .47 & .642 & .01 \\
\hline \multicolumn{6}{|l|}{ Personal support } \\
\hline Number of students mentored & .622 & .345 & 1.80 & .084 & .11 \\
\hline \multicolumn{6}{|l|}{ Mentorship } \\
\hline Number of students mentored* & .19 & .06 & 3.24 & .003 & .29 \\
\hline
\end{tabular}

${ }^{a}$ Unstandardized regression coefficient

${ }^{\mathrm{b}}$ Squared semi-partial correlation

* Indicates significant predictor

$\uparrow$ Indicates marginally significant predictor 
Collectively, these findings indicated that for professors, there is a relationship between well-being, personal and professional supports, and mentorship. Personal and professional support was positively associated with the professional and personal well-being of professors in both countries. Personal and professional support was also associated with positive mentorship practices in Canada.

In Canada, male professors reported higher professional support than female professors and academic self-efficacy predicted higher professional well-being for all participants. This was not the case in Croatia. In Canada, acting as a thesis supervisor was predictive of higher personal and professional well-being, while in Croatia, the number of students previously mentored was predictive of engagement in positive mentorship practices, professional well-being and personal well-being.

\subsection{MEd Students}

For MEd students, perceptions of well-being, support, academic self-efficacy and mentorship were significantly correlated, with the exception of mentorship, which was not significantly related to personal well-being or academic self-efficacy (Table 7).

Table 7. Correlation matrix for MEd student well-being, support, academic self-efficacy and mentorship

\begin{tabular}{lllllll}
\hline & 1 & 2 & 3 & 4 & 5 & 6 \\
\hline 1. Professional well-being & - & & & & & \\
\hline 2. Personal well-being & $.50^{* *}$ & - & & & \\
\hline 3. Professional support & $.57^{* *}$ & $.25^{*}$ & - & & & \\
\hline 4. Personal support & $.49^{* *}$ & $.78^{* *}$ & $.29^{*}$ & - & & \\
\hline 5. Academic self-efficacy & $.31^{* *}$ & $.36^{* *}$ & $.31^{* *}$ & $.48^{* *}$ & - & \\
\hline 6. Mentorship & $.35^{* *}$ & .22 & $.43^{* *}$ & $.30^{*}$ & .21 & - \\
${ }^{*} p<.05 ;{ }^{* *} p<.01$ & & & & &
\end{tabular}

Differences between the two countries were examined (Table 3). Croatian MEd students reported higher personal well-being, $t(75)=2.13, p=.036$, than Canadian MEd students, with no differences in perceptions of professional well-being, $t(75)=.55, p=.587$, academic self-efficacy, $t(75)=1.29, p=.200$, personal support $t(76)=-1.24, p$ $=.219$, professional support $t(75)=1.71, p=.092$, or mentorship practices $t(68)=.47, p=.642$.

A hierarchical regression analysis was completed to examine factors that predicted professional well-being. In step one of the regression gender and study status were entered. In step two, academic self-efficacy, perceived personal support and perceived professional support were entered. Finally, in step three, positive mentorship practice was entered. For Canadian MEd students there was a significant effect of study status, with students studying part-time reporting higher professional well-being (Table 8). At step two, personal and professional support predicted professional well-being for Canadian students. There was no significant effect of mentorship, gender, internationality, type of program, or academic self-efficacy. For Croatian MEd students, study status did not have a significant effect on professional well-being, but there was a significant effect of academic self-efficacy and a significant effect of professional support. Personal support, mentorship and gender had no significant effect on well-being.

Table 8. Hierarchical regression analysis of variables predicting MEd student perceptions of professional and personal well-being in Canada and Croatia

\begin{tabular}{llllllll}
\hline & $\Delta \mathrm{R}^{2}$ & $B^{\mathrm{a}}$ & $\mathrm{SE}$ & $t$-value & $p$-value & $s r^{2 \mathrm{~b}}$ & Observed Power \\
\hline Professional well-being & & & & & & & \\
\hline Canada & & & & & & & \\
\hline Step 1 & .232 & & & & .105 & & .84 \\
\hline \multicolumn{1}{c}{ Gender } & & 2.02 & 2.04 & .993 & .329 & .03 & \\
\hline \multicolumn{1}{l}{ Study Status } & 7.63 & 3.25 & 2.35 & .026 & .15 & \\
\hline
\end{tabular}




\begin{tabular}{|c|c|c|c|c|c|c|c|}
\hline Step 2 & .442 & & & & $<.001$ & & .99 \\
\hline Academic self-efficacy & & -2.58 & 1.44 & -1.79 & .086 & .04 & \\
\hline Personal support & & .543 & .261 & 2.08 & .048 & .06 & \\
\hline Professional support & & 1.29 & .30 & 4.35 & $<.001$ & .25 & \\
\hline Step 3 & .036 & & & & .098 & & .21 \\
\hline Mentorship & & 2.21 & 1.28 & 1.72 & .098 & .04 & \\
\hline \multicolumn{8}{|l|}{ Croatia } \\
\hline Step 1 & .05 & & & & .413 & & .32 \\
\hline Gender & & .48 & 3.89 & .124 & .902 & $<.001$ & \\
\hline Study Status & & -2.48 & 1.84 & -1.35 & .187 & .05 & \\
\hline Step 2 & .41 & & & & $<.001$ & & .99 \\
\hline Academic self-efficacy & & 1.95 & .96 & 2.03 & .052 & .07 & \\
\hline Personal support & & .15 & .23 & .64 & .527 & .01 & \\
\hline Professional support & & .74 & .23 & 3.22 & .003 & .18 & \\
\hline Step 3 & $<.001$ & & & & .935 & & .06 \\
\hline Mentorship & & .08 & 1.02 & .08 & .935 & $<.001$ & \\
\hline
\end{tabular}

\begin{tabular}{|c|c|c|c|c|c|c|c|}
\hline Personal well-being & & & & & & & \\
\hline Canada & & & & & & & \\
\hline Step 1 & .32 & & & & .024 & & .96 \\
\hline Gender & & -1.99 & 2.71 & -.73 & .468 & .01 & \\
\hline Study Status & & 11.91 & 4.32 & 2.75 & .010 & .18 & \\
\hline Step 2 & .30 & & & & .002 & & .90 \\
\hline Academic self-efficacy & & .27 & 2.19 & .124 & .902 & $<.001$ & \\
\hline Personal support & & 1.66 & .40 & 4.20 & $<.001$ & .26 & \\
\hline Professional support & & -.08 & .45 & -.176 & .862 & $<.001$ & \\
\hline Step 3 & .009 & & & & .448 & & .09 \\
\hline Mentorship & & -1.57 & 2.04 & -.77 & .448 & .01 & \\
\hline Croatia & & & & & & & \\
\hline Step 1 & .23 & & & & .011 & & .97 \\
\hline Gender & & 2.29 & 6.52 & .35 & .727 & .003 & \\
\hline Study Status & & -9.89 & 3.09 & -3.20 & .003 & .23 & \\
\hline Step 2 & .44 & & & & $<.001$ & & .99 \\
\hline Academic self-efficacy & & .44 & 1.40 & .316 & .754 & .001 & \\
\hline Personal support & & 1.65 & .34 & 4.83 & $<.001$ & .25 & \\
\hline Professional support & & .24 & .33 & .71 & .484 & .005 & \\
\hline Step 3 & $<.001$ & & & & .907 & & .06 \\
\hline Mentorship & & .176 & 1.49 & .118 & .907 & $<.001$ & \\
\hline
\end{tabular}

\footnotetext{
${ }^{\mathrm{a}}$ Unstandardized regression coefficient

${ }^{\mathrm{b}}$ Squared semi-partial correlation
} 
Another hierarchical regression analysis was completed to examine factors that predicted personal well-being. In step one of the regression gender and study status were entered. In step two, academic self-efficacy, perceived personal support and perceived professional support were entered and in step three, positive mentorship practice was entered. Similar patterns found for professional well-being were also found for personal well-being (Table 8). For Canadian MEd students, there was a significant effect for study status such that part-time students reported higher personal well-being. There was also a significant effect of personal support, but no effect of professional support, academic self-efficacy, gender, study status, or mentorship practices. For Croatian MEd students, there was a significant effect of study status on personal well-being, with part-time students reporting lower personal wellbeing. There was also a significant effect of personal support, but no effect of professional support, academic self-efficacy, gender, or mentorship.

Collectively these results suggest that for graduate students in Canada and Croatia, the relationship between well-being, support, self-efficacy and mentorship is complex. Students in both countries, who felt supported professionally and personally, reported greater professional and personal well-being respectively. Self-efficacy may make a difference for Croatian students but seemed to have little unique impact on Canadian students. Studying part-time in Canada was associated with higher personal and professional well-being but was associated with lower personal well-being in Croatia. Mentorship practices seemed to have little effect on well-being in either country.

\subsection{Professors and MEd Students}

The final analyses addressed whether there were differences between perceptions of well-being, support, and mentorship among professors and MEd students as a function of country (Table 3). For Canadians, the overall MANOVA was significant, $F(6,96)=28.63, p<.001$. In particular, there was a significant difference between MEd students and professors in personal well-being $F(1,96)=21.46, p<.001$ (observed power $=1.00$ ), personal support, $F(1,96)=113.34, p<.001$, (observed power $=1.00$ ), and marginally, professional well-being, $F(1,96)=$ $3.83, p=.053$, (observed power $=.49$ ), . There was no significant difference between MEd students and professors in their perceptions of professional support $F(1,96)=.30, p=.585$, (observed power $=.08$ ), mentorship, $F(1,96)$ $=2.45, p=.120$, (observed power $=.34$ ), or academic self-efficacy, $F(1,96)=.16, p=.690$ (observed power $=.07)$. For Croatians, the overall MANOVA was also significant, $F(6,58)=11.04, p<.001$. There were significant differences between MEd students and professors in professional well-being $F(1,58)=7.58, p=.008$, (observed power $=.77$ ), personal support, $F(1,58)=20.35, p<.001$, (observed power $=1.00)$, and professional support, $F(1$, $58)=11.32, p=.001$ (observed power $=.97$ ). There was no significant difference between MEd students and professors in their perceptions of personal well-being, $F(1,58)=.03, p=.873$, (observed power $=.05)$, mentorship, $F(1,58)=22, p=.639$, (observed power $=.08$ ), or academic self-efficacy, $F(1,58)=1.81, p=.184$, (observed power $=.26$ ). Collectively, professors reported overall higher well-being and support than MEd students.

\section{Discussion}

The findings of this study support and extend previous literature exploring relationships between personal and professional support, autonomy, relatedness and subjective experiences of well-being among professors and MEd students. Canadian professors reported greater experiences of well-being and self-efficacy than did their Croatian counterparts, with this being especially true for male participants. Professors reported higher subjective experiences of well-being than did MEd students. Professional and personal support positively impacted various aspects of subjective experiences of well-being, as did perceptions of positive mentoring relationships.

\subsection{Professors: Well-Being, Self-Efficacy and Gender}

Canadian professors reported higher experiences of personal well-being and academic self-efficacy relative to their Croatian colleagues. These findings, in part, may reflect socio-cultural and institutional differences between the two countries. Croatia is one of the European countries with the lowest index of economic development and national prosperity (Legatum Institute, 2015; United Nations Development Programme, 2014). Economic underdevelopment, income inequality, unemployment, underemployment, social welfare, and political instability, are known to negatively impact individuals' experiences of well-being (Jorm \& Ryan, 2014; Ngamaba, Panagioti, $\&$ Armitage, 2017).

Canadian professors who participated in this study were significantly older and held higher rank (i.e., associate professor, full professor) than their Croatian colleagues. Attainment of rank is an attestation of scholarly proficiencies and capacities and is likely reflected in these professors' reported sense of self-efficacy (Lumpkin, 2014). Careers in academia can be conceptualized across a continuum of stages extending from early- to mid- and late-career. 
In general, early-career professors tend to experience insecurity, isolation, and stress (Lumpkin, 2014). Early-career faculty report concerns related to achieving employment permanency, with these concerns exacerbated by high performance expectations and/or unclear promotion processes and criteria (Ortlieb \& Weiss, 2018). These professors also report being intensively focused on developing research competencies and gaining scholarly recognition (Albert, Davia, \& Legazpe, 2018). Additionally, early-career professors are often developing instructional curriculum, navigating teaching demands, and negotiating service expectations. Collectively, these requirements may result in competing senses of urgency, demanding workloads, intensive work hours, and overall reduced perceptions of well-being for early-career professors (Lumpkin, 2014).

Stressors associated with the profession are often exacerbated for female professors, who in addition to institutional performance-related pressures, often face additional considerations related to familial responsibilities including raising children, securing partner employment and/or elder-care (Fritsch, 2015). Women are twice as likely as men to report experiencing stress within academia (Hurtado, Alvarez, Guillermo-Wann, Cuellar, \& Arellano, 2012). In this study, Canadian female professors also reported experiences of lower professional well-being relative to their male colleagues.

In North America and Europe, universities are recognized as gendered institutions whose organizational, instructional, and funding structures; policies; practices; and cultural presumptions reflect masculine principles, generate gendered divisions of labor, and bolster men's careers while impeding women's professional advancement (Fumasoli, Goastellec, \& Kehm, 2015; Leathwood, 2013). While men's roles in academia are well defined, promoting their sense of belonging, security and comfort in the academy, competing demands associated with work and family may increase women's sense of isolation and diminish their abilities to establish and nurture positive collegial relationships (Penney et al., 2015).

Subjective reports of greater well-being by Canadian male professors relative to their female counterparts, may also be reflective of other systemic inequities within academia. Despite the ongoing implementation of legislation, policies, and practices intended to promote equity, and despite considered advancement in the profession, women remain disproportionately underrepresented and underpaid among the professoriate ranks (CAUT, 2018). This is especially true in Faculties of Education where women hold over two-thirds of the available teaching positions. It is well documented that underemployment and precarious employment undermine individuals' sense of subjective well-being (Brand, 2015; Redekopp \& Huston, 2019).

Croatian professors however did not differ in their reported experiences of subjective well-being as a function of gender. The Croatian government has created recent legislative frameworks which specifically task Faculties of Education to minimize and eliminate gender inequality in Croatian society (Gender Equality Office of the Government of the Republic of Croatia, 2014). All teachers and future teachers are mandated to be trained in gender equality principles, with the intention that gender stereotypes be eliminated from Croatian society and that gender balance be achieved in the occupation over the next several years. It is thus possible that female professors in Croatia perceive themselves as active agents in promoting gender equality in society, and therefore, do not rank their subjective well-being as any lower than their male colleagues. Consistent with this interpretation, Croatian professors in this study reported significantly greater experiences of professional support compared to Canadian counterparts. Subjective feelings of professional support, in part, may reflect the efforts and outcomes to satisfy mandated legislations and responsibilities.

\subsection{MEd Students: Well-Being, Study Status and Gender}

Professors reported significantly greater experiences of subjective well-being than did MEd students across both countries. This finding is not surprising in context of the demands, uncertainties and challenges associated with graduate studies. Engagement in graduate studies is an intensive, difficult and stressful experience for many students. Graduate students commonly report challenges associated with intensive coursework and demanding timelines. Many graduate students, especially women, face additional challenges related to managing multiple and often competing personal and professional roles that may include student, working professional, caregiver, and partner. Croatian MEd students reported a higher sense of personal well-being relative to their Canadian counterparts. Croatian students were significantly younger than their Canadian peers and thus, potentially more likely to be the recipients of familial support from parents or significant others. At the same time, these younger adults may be less likely to hold familial responsibilities for children, partners or parents.

Post-graduation employment opportunities may have impacted MEd students' sense of well-being. In this study, professional support impacted Croatian students' subjective experiences of well-being. It is likely that receiving support from their instructors and relevant others at the university increased these students' sense of readiness for entry into the profession and optimism for the future. Unlike their Canadian peers, Croatian students will graduate 
into an era of teaching shortages with demands for skilled educators anticipated to continue over the foreseeable future (European Commission, 2019). Canadian students, on the other hand, enter a workforce where they are likely to experience employment uncertainty and insecurity due to increasingly competitive job markets, limited teaching and postsecondary positions, and increased contract, part-time and precarious positions (Ontario College of Teachers, 2019).

For Canadian students, part-time studies, personal and professional support predicted professional well-being. Engaging in part-time studies is often associated with holding part-time employment which may lessen immediate financial concerns and enhance opportunities for subsequent employment (Woods \& Frogge, 2017). On the other hand, the need to balance school, work, and personal needs may be exacerbated for part-time students (Castelló, Pardo, Sala-Bubaré, \& Suñe-Soler, 2017). School-work-life balance has been identified as a major challenge for completing graduate studies, with many of these students also reporting a lack of support (Grabowski, 2016; McAlpine et al., 2012). In the current study, we examined part-time status alongside support, which may suggest that engaging in part-time studies while being the recipient of personal and professional support may increase sense of professional well-being for Canadian students.

\subsection{Professional and Personal Support and Well-Being}

Consistent with SDT (Deci \& Ryan, 1985; Ryan \& Deci, 2000), perceived levels of professional and personal support were positively associated with subjective experiences of well-being for professors and MEd students in both countries, although not in precisely the same ways. Personal and professional support predicted well-being for professors. Professional support predicted well-being for MEd students in Croatia, while personal support predicted well-being for MEd students in Canada. These findings add to existing literature demonstrating that SDT needs, such as personal and professional supports, directly and indirectly predict well-being in tenured, tenure-track and non-tenured professors (Larson, Shelley, \& Gahn, 2015; Larson et al., 2019; Seipel \& Larson, 2018). Similarly, instructors and peers are known to play a crucial and unique role in creating academic environments that are perceived to be supportive of students' well-being (Schenkenfelder, Frickey \& Larson, 2020).

\subsection{Mentoring}

Professors in both countries who felt both personally and professionally supported were more likely to engage in positive mentoring practices. Presumably, professors who feel supported are more likely to engage in growth-fostering relational processes including mentoring. As professors engage in positive mentoring and other relational processes, they are likely to experience a sense of revitalization, which, in turn, works to sustain and motivate their efforts to support others (Schwartz \& Holloway, 2012). In this study, Canadian professors who were thesis supervisors, and thus likely engaged in intensive one-on-one mentoring relationships, reported higher personal and professional well-being. Similarly, the number of students mentored positively predicted Croatian professors' engagement in mentoring practices as well as their personal and professional well-being.

For MEd students in both countries, mentoring did not predict professional or personal well-being. A positive correlation was found, however, between professional support and mentoring. Within academia, professional support includes a variety of institutional practices and structures as well as interactions with significant others including peers and instructors. In this way, mentoring may represent one form of professional support available to students. Schmidt and Hansson (2018) found that the relationships that doctoral students formed with peers, supervisors and the scholarly community at large collectively contributed to their sense of well-being. Presumably these experiences would extend to MEd students. General experiences of feeling supported may positively impact MEd students' sense of well-being beyond the relationship with any single faculty member mentor, consistent with findings that graduate students require multiple support structures in order to advance their learning goals and support their well-being (Lorenzetti et al., 2019). The role of professional support is likely to become increasingly important as the nature of master's programs continue to evolve and change to include more course-based, blended and online delivery models. In these instances, the role of the academic mentor, such as the faculty supervisor, may transform as fewer students interact one-on-one and face-to-face with professors to complete research intense projects and course-based activities.

\subsection{Limitations}

In exploring the relationships between professor and MEd student subjective reports of well-being, personal and professional support, and mentoring experiences, the findings of this study provide insights about how well-being can be supported within higher education. There are, however, several limitations associated with this study that need to be acknowledged. The sample size was relatively small, potentially limiting power, and there was an imbalance in the number of professor and student participants in each country. More Canadian professors 
participated in this study than did Croatian professors, while more Croatian MEd students participated than did Canadian MEd students. Professors were also recruited much more widely than were MEd students, allowing for more varied reflections of institutional experiences within this group. Additionally, our examinations of faculty well-being and support were based on an adjusted version of the Skovholt Practioner Professional Resiliency and Self-Care Inventory, but we were not able to examine the full psychometric properties of our changes with the current data set, future research should examine the relationship between support and well-being with more robust measures. Finally, differences in the educational systems in each country were not widely explored, nor were individual differences of experience based on race, ethnicity, sociocultural status, or years as a student/professor. For instance, Croatia hosts more refuges than Canada (Marsanic et al., 2017) making it more likely that some students enrolled in graduate studies hold complex prior experiences that impact their sense of well-being beyond their postsecondary experiences. In addition, students' experiences with off-campus supports and social services were not explored here leaving questions about the intersectionality between their on-campus and off-campus experiences.

\subsection{Conclusion and Implications}

Overall, this study illustrates the importance of feeling relationally supported within the academy. In both countries, professors and MEd students who felt personally and professionally supported reported greater subjective well-being. This was true despite the interaction with other variables including study status, academic self-efficacy, gender and permanency which had varying effects across the participant groups. Importantly, however, MEd students did report lower levels of subjective well-being than their professors.

Lower levels of well-being reported by MEd students may be rooted in graduate students' need for multiple support structures within the university itself (Lorenzetti et al., 2019). Some of the supports graduate students require that have been identified in the literature include academic, psychological, social and career supports. Support for the acquisition of procedural and disciplinary knowledge, academic thinking and writing skills, time management skills, self-confidence and motivation, coping with stress, academic socialization, interpersonal skills, the establishment of personal and professional networks, self-care and the development of career competencies have all been shown to be important to the well-being of graduate students (Lorenzetti et al., 2019). Further explorations of the provision of these supports by universities and their impacts on graduate students may help reduce the gap between the reported experiences of subjective well-being among professors and MEd students.

As enrolment numbers in master's level programs continue to increase (Wall et al., 2018), it is incumbent on university administrators to consider the unique nature of graduate-level studies and the relational needs of both professors and students (Deci \& Ryan, 1985; Ryan \& Deci, 2000). Capping class sizes at 15 or fewer students, providing peer-mentoring programs to MEd students and professors, delivering robust orientation sessions that outline on-campus and community-based academic, psychological, social and career supports, and increasing the number of university sponsored communities of learning and social activities are strategies that increase awareness and access to personal and professional support in graduate programs (Benshoff, Cashwell, \& Rowell, 2015; Lorenzetti et al., 2019). Additionally, developing university-based counseling services designed specifically for graduate students' unique needs and training academic advisors to be able to connect graduate students with other support services on campus or in the community that are appropriate for them is important to the well-being of graduate students (Benshoff, Cashwell, \& Rowell, 2015; Lorenzetti et al., 2019).

Continued efforts to achieve gender equity among the professoriate is another crucial initiative that must be maintained and strengthened to increase the well-being of both faculty members and graduate students. This involves examining, and eliminating, the gendered landscapes in our curriculum, pedagogical practices, career prospects, university administration and the ways we celebrate researchers and scholarship in our fields (Alrashidi, 2017; Angervall, 2018).

Finally, increased formal recognition for engaging in relational practices, such as mentoring, by including them in the promotion and tenure process and in workload considerations for professors would help increase the well-being of the professorate. By including evidence of engaging in relational practices with students as part of the tenure and promotion process and including the mentoring and supervision of graduate students as a formal part of professors' workload these relational practices would be considered important and would increase in universities. In these ways, the university administration, professors and graduate students can each create collective, compatible goals that work to foster individuals' ongoing learning successes and well-being. 


\section{Acknowledgements}

The authors wish to thank Drs. Branko Bognar, Sinisa Opic in Croatia, and Mira Bajovic and Catherine Hands in Canada for their contributions to this research project. This research study was funded by a Brock University Social Sciences and Humanities Research Council Institutional Grant (BSIG Grant).

\section{References}

Adlaf, E. M., Demers, A., \& Gliksman, L. (2005). Canadian campus survey, 2004. Retrieved from http://www.camh.net/Research/Areas_of_research/Population_Life_Course_Studies/CCS_2004_repor t.pdf

Albert, C., Davia, M., \& Legazpe, N. (2018). Job satisfaction amongst academics: The role of research $\begin{array}{llll}\text { productivity. Studies in Higher Education, 43(8), } & \text { 1362-1377. }\end{array}$ https://doi.org/10.1080/03075079.2016.1255937

Alrashidi, K. M. A. (2017). State of women in academia: extent of supportive environment for female researchers. Journal of Educational and Social Research, 7(1), 13-17.

Anderson, D. S. (2019). Wellness for the future. In D. S. Anderson (Ed.), Further wellness issues for higher education: How to promote student health during and after college (pp. 1-6). New York: NY, Routledge.

Angervall, P. (2018). The academic career: A study of subjectivity, gender and movement among women university lecturers. Gender and Education, 30(1), 105-118.

Benshoff, J., Cashwell, C., \& Rowell, P. (2015). Graduate students on campus: Needs and implications for college counselors. Journal of College Counseling, 18(1), 82-94. https://doi.org/10.1002/j.2161-1882.2015.00070.x

Blagg, K. (2018). The rise of master's degrees: Master's programs are increasingly diverse and online. Washington. DC: Urban Institute.

Brand, J. E. (2015). The far-reaching impact of job loss and unemployment. Annual Review of Sociology, 41(1), 359-375. https://doi.org/10.1146/annurev-soc-071913-043237

Buric, I., Sliskovic, A., \& Penezic, Z. (2019). Understanding teacher well-being: A cross-lagged analysis of burnout, negative student-related emotions, psychopathological symptoms and resilience. Educational Psychology, 39(9), 1136-1155.

Canadian Association of University Teachers (CAUT). (2018). Underrepresented and underpaid: Diversity \& equity among Canada's post-secondary education teachers. Retrieved from https://www.caut.ca/sites/default/files/caut_equity_report_2018-04final.pdf

Castelló, M., Pardo, M., Sala-Bubaré, A., \& Suñe-Soler, N. (2017). Why do students consider dropping out of doctoral degrees? Institutional and personal factors. Higher Education, 74(6), 1053-1068. https://doi.org/10.1007/s10734-016-0106-9

Darabi, M., Macaskill, A., \& Reidy, L. (2016). Stress among UK academics: Identifying who copes best. Journal of Further and Higher Education, 41(3), 393-412. http://doi.org/10.1080/0309877X.2015.1117598

Deci, E. L., \& Ryan, R. M. (1985). Intrinsic motivation and self-determination in human behavior. New York: NY, Plenum.

Dodge, R., Daly, A. P., Huyton, J., \& Sanders, L. D. (2012). The challenge of defining wellbeing. International Journal of Wellbeing, 2(3), 222-235. https://doi.org/10.5502/ijw.v2i3.4

English, L., \& Avakian, L. (2012). Transforming higher education through faculty wellbeing. Horizons Workforce Consulting. $\quad$ Retrieved from https://solutionsatwork.brighthorizons.com/-/media/bh/saw/pdfs/highered/2012_higher-ed-transform-wellbe ing_paper.ashx?la=en

European Agency for Special Needs and Inclusive Education. (2018). Raising the achievement of all learners in inclusive education: Lessons from European policy and practice. Odense, Denmark: Author.

European Commission. (2019). Education and training monitor 2019: Croatia. Luxembourg: Publications Office of the European Union.

Evans, T. M., Bira, L., Beltran Gastelum, J., Todd Weiss, J., \& Vanderford, N. L. (2018). Evidence for a mental health crisis in graduate education. Nature Biotechnology, 36(3), 282-284.

Frank, J. L., Reibel, D., Broderick, P., Cantrell, T., \& Metz, S. (2015). The effectiveness of mindfulness-based stress reduction on educator stress and well-being: Results from a pilot study. Mindfulness, 6(3), 208-216. 
Fritsch, N. S. (2015). At the leading edge - Does gender still matter? A qualitative study of prevailing obstacles and successful coping strategies in academia. Current Sociology, 63(4), 547-565. https://doi.org/10.1177/0011392115576527

Fumasoli, T., Goastellec, G., \& Kehm, B. M. (2015). Understanding change in the academic profession through the perceptions of academics and institutional leadership. In T. Fumasoli, G. Goastellec, \& B. M. Kehm (Eds.), Academic work and careers in Europe: Trends, challenges, perspectives (pp. 1-12). Zurich, Switzerland: Springer International Publishing.

Gender Equality Office of the Government of the Republic of Croatia. (2014). Report by the Republic of Croatia on the application of the Beijing declaration and platform for action (1995) and the results of the $23^{\text {rd }}$ special session of the UN general assembly (2000) - Beijing + 20. Zagreb, Croatia: The Printer for the Republic of Croatia.

Grabowski, C. (2016). Today's nontraditional college student: Challenges to academic success and degree completion. Inquiries Journal, 8(3), 1-8. $\quad$ Retrieved from http://www.inquiriesjournal.com/articles/1377/2/todays-nontraditional-student-challenges-to-academic-succ ess-and-degree-completion

Gulati, G., Lele Mookerjee, A., \& Rajput, V. (2018). In H. Henning (Ed.), Wellbeing in higher education. Cultivating a healthy lifestyle among faculty and students (pp. 44-56). New York, NY: Routledge.

Gullan, R. L., Bauer, K., Korfiatis, P., DeOliveira, J., Blong, K., \& Docherty, M. (2016). Development of a quantitative measure of the mentorship experience in college students. Journal of College Student Development, 57(8), 1049-1055.

Henning, M. A., Krägeloh, C. U., Dryer, R., Moir, F., Billinton, D. R., \& Hill, A. G. (2018). Wellbeing in higher education. Cultivating a healthy lifestyle among faculty and students. New York, NY: Routledge.

Higher Education Quality Council of Ontario. (2018). Master's degree enrolment in Ontario universities. Retrieved from http://www.heqco.ca/en-ca/Research/quickstats/Pages/qs_2_6.aspx

Houle, R. (2019). Results from the 2016 census: Refugees who resettled in Canada in 2016 and 2016. Ottawa, ON: Statistics Canada.

Hurtado, S., Alvarez, C., Guillermo-Wann, C., Cuellar, M., \& Arellano, L. (2012). A model for diverse learning environments: The scholarship on creating and assessing conditions for student success. In M. B. Paulsen (Ed.), Higher education: Handbook of theory and research (pp. 41-122). New York, NY: Springer.

Jaworska, N., De Somma, E., Fonseka, B., Heck, E., \& MacQueen, G. M. (2016). Mental health services for students at postsecondary institutions: A national survey. Canadian Journal of Psychiatry, 61(12), 766-775.

Jordan, J. V. (2010). Relational-cultural therapy. Washington: DC, American Psychological Association.

Jorm, A. F., \& Ryan, S. M. (2014). Cross-national and historical differences in subjective well-being. International Journal of Epidemiology, 43(2), 330-340.

Jovanovic, V. (2019). Evaluation of domain satisfaction measure in cross-national perspective: Evidence from Austria and four countries of the former Yugoslavia. Social Indicators Research, 141(3). https://doi.org.proxy.library.brocku.ca/10.1007/s11205-018-1879-2

Kim, J. (2016). Global cultural capital and global positional competition: International graduate students' transnational occupational trajectories. British Journal of Sociology of Education, 37(1), 30-50.

Kinman, G. (2019). Effort-reward imbalance in academic employees: Examining different reward systems. International Journal of Stress Management, 26(2), 184-192.

Kinman, G., \& Wray, S. (2013). Higher stress: A survey of stress and wellbeing among staff in higher education. London, UK: UCU Publications.

Larson, L. M., Shelley, M. C., \& Gahn, S. W. (2015). Self-determination theory. COACHE, and faculty outcomes in higher education: Institutions and individuals. Paper presented at Building an Institutional Framework for Faculty Success Conference, Evanston, Illinois.

Larson, L., Seipel, M., Shelley, M., Gahn, S., Ko, S., Schenkenfelder, M., ... Heitmann, M. (2019). The academic environment and faculty well-being: The role of psychological needs. Journal of Career Assessment, 27(1), 167-182. https://doi.org/10.1177/1069072717748667 
Leathwood, C. (2013). Re/presenting intellectual subjectivity: Gender and visual imagery in the field of higher education. Gender and Education, 25(2), 133-154.

Legatum Institute. (2015). The Legatum Prosperity Index, 2015. London, UK: Author.

Lorenzetti, D. L., Shipton, L., Nowell, L., Jacobsen, M., Lorenzetti, L., Clancey, T., ... Paolucci, E. O. (2019). A systematic review of graduate student peer mentorship in academia. Mentoring \& Tutoring: Partnership in Learning, 27(5), 549-576.

Lucey, T. A., \& White, E. S. (2017). Mentorship in higher education: Compassionate approaches supporting culturally responsive pedagogy. Multicultural Education, 24(2), 11-17.

Lumpkin, A. (2014). The role of organizational culture on and career stages of faculty. The Educational Forum, 78(2), 196-205. https://doi.org/10.1080/00131725.2013.878420

Manwell, L. A., Barbic, S. P., Roberts, K., Durisko, Z., Lee, C., Ware, E., ... McKenzie, K. (2015). What is mental health? Evidence towards a new definition from a mixed methods multidisciplinary international survey. $B M J$ Open, e007079.

Marsanic, V. B., Franic, T., \& Aurkovic, K. D. (2017). Mental health issues of refugee children: lessons from Croatia. European Child and Adolescent Psychiatry, 26, 377-381.

McAlpine, L., Paulson, J., Gonsalves, A., \& Jazvac-Martek, M. (2012). 'Untold’ doctoral stories: Can we move beyond cultural narratives of neglect?. Higher Education Research \& Development, 31(4), 511-523. https://doi.org/10.1080/07294360.2011.559199

Miller, J. B. (1986). Toward a new psychology of women (2nd ed.). Boston: MA. Beacon Press.

Miller, J. B., \& Stiver, I. P. (1997). The healing connection: How women form relationships in therapy and in life. Boston: MA, Beacon Press.

Neves, J., \& Hillman, N. (2018). Student academic experience survey. 2019. Higher Education Policy Institute (HEPI). $\quad$ Retrieved from https://www.hepi.ac.uk/wp-content/uploads/2019/06/Student-Academic-Experience-Survey-2019.pdf

Ng, J. Y., Ntoumanis, N., Thøgersen-Ntoumani, C., Deci, E. L., Ryan, R. M., Duda, J. L., ... Williams, G. C. (2012). Self-determination theory applied to health contexts a meta-analysis. Perspectives on Psychological Science, 7(4), 325-340.

Ngamaba, K. H., Panagioti, M., \& Armitage, C. J. (2017). How strongly related are health status and subjective well-being? Systematic review and meta-analysis. European Journal of Public Health, 27(5), 879-885.

Ontario College of Teachers. (2019). Transition to teaching 2019. Ontario College of Teachers: Toronto, ON. Retrieved from https://www.oct.ca//media/Transition\%20to\%20Teaching\%202019/2019T2TMainReportENWEB.pdf

Organization for Economic Co-Operation and Development (OECD). (2019). Results from TALIS 2018 Country Note: Croatia. Retrieved from https://www.oecd.org/education/talis/TALIS2018_CN_HRV.pdf

Ortlieb, R., \& Weiss, S. (2018). What makes academic careers less insecure? The role of individual-level antecedents. Higher Education, 76(4), 571-587. https://doi.org/10.1007/s10734-017-0226-x

Pappano, L. (2011, July). The Master's as the new Bachelor's. New York Times. Retrieved from https://www.nytimes.com/2011/07/24/education/edlife/edl-24masters-t.html

Penney, S., Young, G., Badenhorst, C., Goodnough, K., Hesson, J., Joy, R., ... Pelech, S. (2015). Faculty writing groups: A support for women balancing family and career on the academic tightrope. The Canadian Journal of Higher Education, 45(4), 457-459.

Redekopp, D., \& Huston, M. (2019). The broader aims of career development: Mental health, wellbeing and work. $\begin{array}{lllll}\text { British Journal of Guidance \& } & \text { Counselling, 47(2), } 257 .\end{array}$ https://doi.org/10.1080/03069885.2018.1513451

Rose, M. (2013). Graduate student professional development: A survey with recommendations. Ottawa, ON: Social Sciences and Humanities Research Council of Canada.

Ryan, R. M., \& Deci, E. L. (2000). Self-determination theory and the facilitation of intrinsic motivation, social development, and well-being. American Psychologist, 55(1), 68-78.

Schenkenfelder, M., Frickey, E. A., \& Larson, L. M. (2020). College environment and basic psychological needs: Predicting academic major satisfaction. Journal of Counseling Psychology, 67(2), 265-273. 
Schmidt, M., \& Hansson, E. (2018). Doctoral students' well-being: A literature review. International Journal of Qualitative Studies on Health and Well-being, 13(1), 1-14.

Schwartz, H. L., \& Holloway, E. L. (2012). Partners in learning: A grounded theory study of relational practice between master's students and professors. Mentoring \& Tutoring: Partnership in Learning, 20(1), 115-135.

Schwartz, H. L., \& Holloway, E. L. (2014). 'I become a part of the learning process': Mentoring episodes and individualized attention in graduate education. Mentoring \& Tutoring: Partnership in Learning, 22(1), 38-55.

Seipel, M., \& Larson, L. (2018). Supporting non-tenure-track faculty well-being. Journal of Career Assessment, 26(1), 154-171. https://doi.org/10.1177/1069072716680046

Sisask, M., Varnik, P., Varnik, A., Apter, A., Balazs, J., Balint, M., ... Wasserman, D. (2013). Teacher satisfaction with school and psychological well-being affects their readiness to help children with mental health problems. Health Education Journal, 73(4), 1-12.

Skovolt, T. M. (2016). Skovolt practitioner professional resiliency and self-care inventory. In T. M. Skovolt, \& M. Trotter-Mathison (Eds.), The resilient practitioner: Burnout and compassion fatigue prevention and self-care strategies for the helping professions (3rd ed.). New York, NY: Routledge.

Statistics Canada. (2016). Census of population, Statistics Canada catalogue No. 98-400-X2016295. Ottawa, ON: Author.

Thorley, C. (2017). Not by degrees: Improving student mental health in the UK's universities. Institute for Public Policy Research. IPPR. Retrieved from http://www.ippr.org/research/publications/not-by-degrees

United Nations Development Program. (2014). Assessment of development results: Croatia. New York, NY: Author.

Wall, K., Zhao, J., Ferguson, S. J., \& Rodriguez, C. (2018). Results from the 2016 census: Is field of study a factor in the payoff of a graduate degree?. Statistics Canada. Retrieved from https://www150.statcan.gc.ca/n1/pub/75-006-x/2018001/article/54978-eng.htm

Woloshyn, V. E., Savage, M. J., Ratković, S., Hands, C., \& Martinovic, D. (2019). Exploring professors' experiences supporting graduate student well-being in faculties of education. International Journal of Mentoring and Coaching in Education, 8(4), 397-411.

Woods, K., \& Frogge, G. (2017). Preferences and experiences of traditional and nontraditional university students. The Journal of Continuing Higher Education, 65(2), 94-105. https://doi.org/10.1080/07377363.2017.1318567

\section{Copyrights}

Copyright for this article is retained by the author(s), with first publication rights granted to the journal.

This is an open-access article distributed under the terms and conditions of the Creative Commons Attribution license (http://creativecommons.org/licenses/by/4.0/). 